\title{
Resection of a giant gastric mass using an ultrasonic scalpel with endoscopic assistance
}

A 55-year-old woman presented with melena of 4 days' duration. Upper endoscopy showed a giant pedunculated mass, about $6 \mathrm{~cm}$ in size, in the gastric cardia, with hyperemia and erosion ( $\mathbf{F i g} \mathbf{1}$ ). Histopathology of biopsies found no evidence of malignancy, and endoscopic ultrasonography showed a low-echoic mass with nonhomogeneous echo ( Fig.2). Considering the high risk of bleeding associated with endoscopic resection of such a thick stalk of the mass, and because the patient refused recommended surgical resection, we planned to resect the mass by using an ultrasonic scalpel through a gastric fistula formed by percutaneous endoscopic gastrostomy (PEG).

First, we performed the PEG procedure. Endoscopic treatment was performed 2 weeks later, when the gastric fistula was formed. The patient was under general anesthesia. We introduced a conventional upper endoscope and removed the gastrostomy tube using a grasping forceps. Next we inserted a 5-mm trocar through the gastric fistula and inserted an ultrasonic scalpel (Harmonic ACE; Ethicon Endo-Surgery, Inc., Cincinnati, Ohio, USA) into the stomach through the trocar. Under endoscopic view, we easily resected the mass using the ultrasonic scalpel, with no adverse events ( $\mathbf{F i g . 3 ;}$

- Video 1). Finally, we successfully removed the giant mass after using a snare to cut it into small pieces ( $>$ Fig.4). The abdominal wound was covered by sterile gauze.

Postoperative pathology was interpreted as a hamartoma with low grade dysplasia. On 1-month follow-up, upper endoscopy showed a white scar in the gastric cardia ( $>$ Fig.5) and abdominal wound healing; no delayed complications were recorded.

We present here a special case in which a surgical device was used for resecting a giant mass in the gastric cardia with endoscopic assistance. This method was
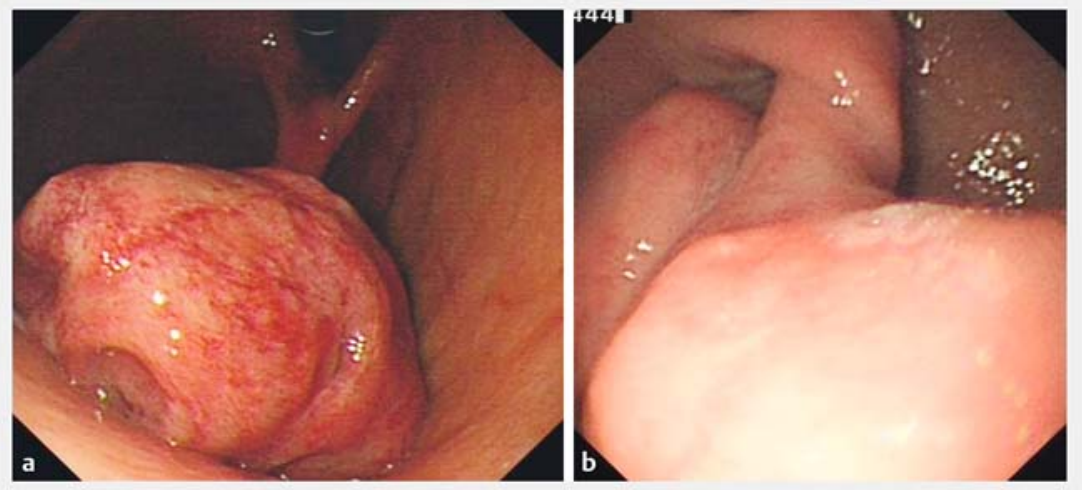

-Fig. 1 Preoperative upper endoscopy showed a giant pedunculated mass, about $6 \mathrm{~cm}$ in size, in the gastric cardia, with hyperemia and

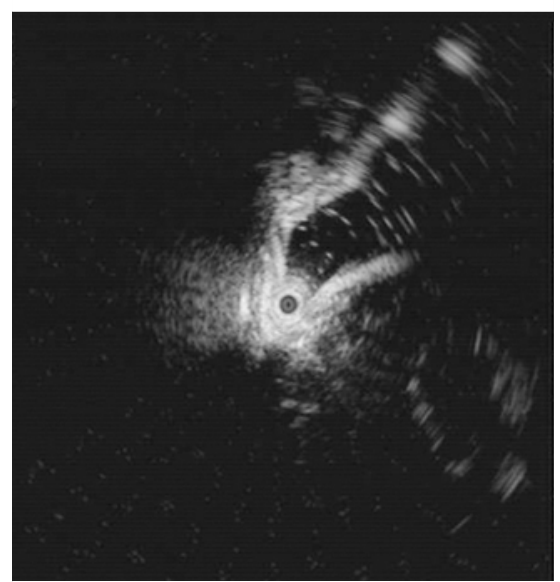

Fig. 2 Endoscopic ultrasonography showed a low-echoic mass with nonhomogeneous echo.

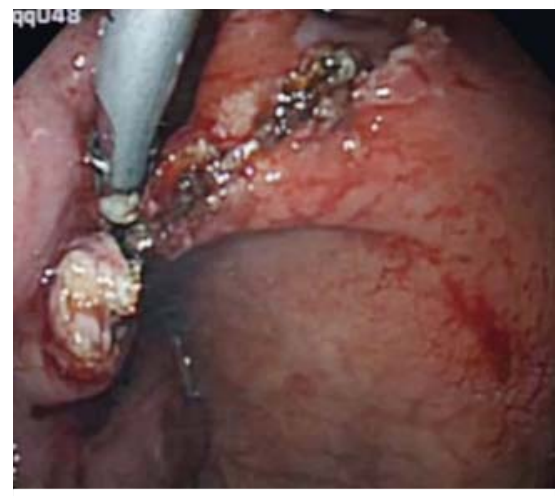

Fig. 3 Under endoscopic view, the mass was easily resected using the ultrasonic scalpel.
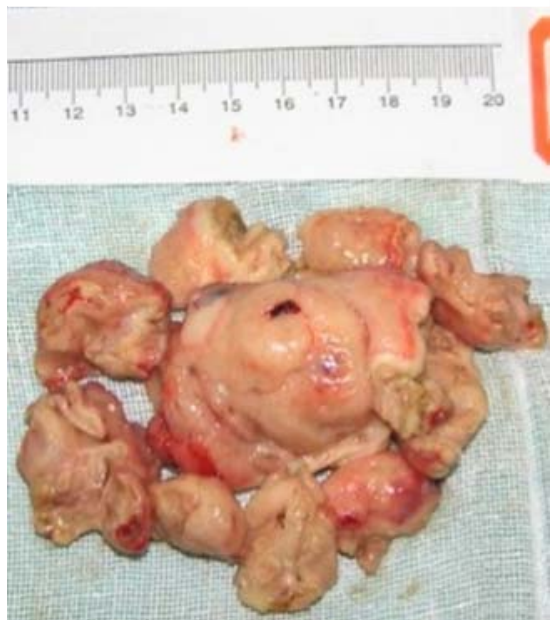

Fig. 4 The giant mass was successfully removed by using a snare to cut it into small pieces.

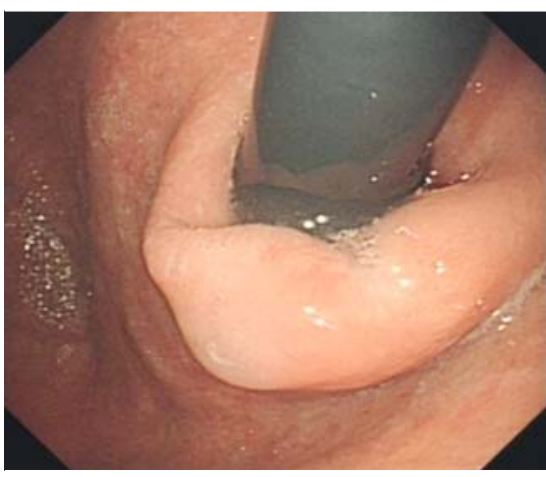

- Fig. 5 Postoperative upper endoscopy showed a white scar in the gastric cardia. 


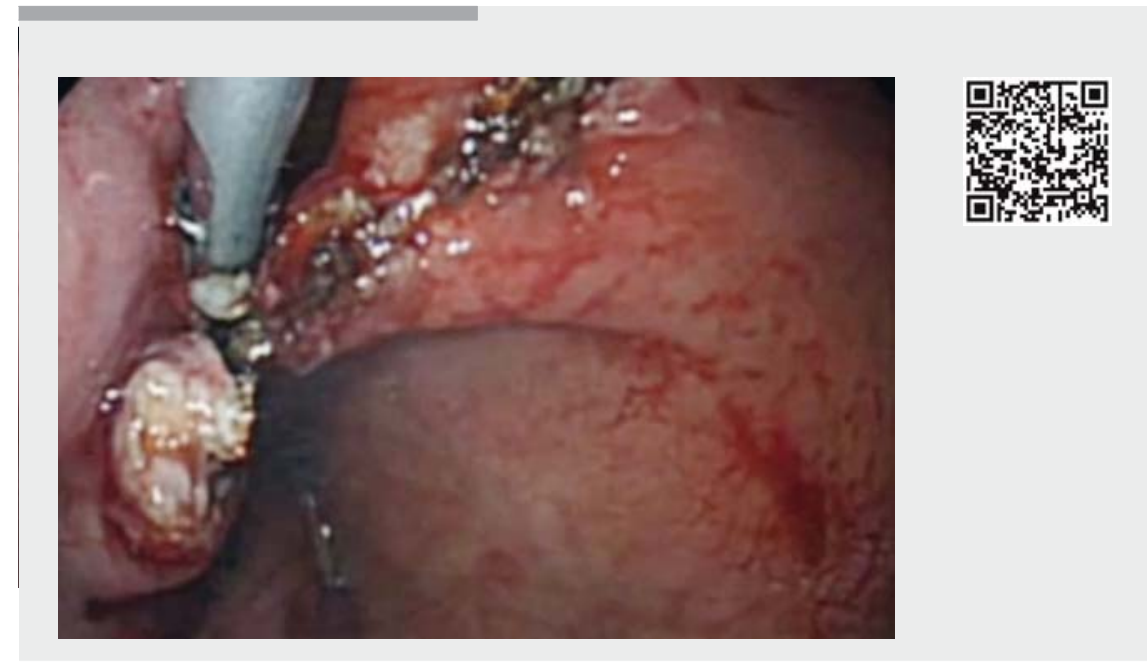

$\checkmark$ Video 1 Use of an ultrasonic scalpel with endoscopic assistance to resect a giant gastric mass in a 55-year-old woman.

relatively safe and may be an option for the treatment of certain lesions that are difficult to access using endoscopy alone and need the assistance of surgical devices.

Endoscopy_UCTN_Code_TTT_1AT_2AD

\section{Acknowledgment}

We want to thank National Key R\&D Program of China, 2017YFC0112305 for their support.

\section{Competing interests}

None
Xiang-lei Yuan*, Shui-fang Wang*, Lian-song Ye, Chun-cheng Wu, Xian-hui Zeng, Naveed

Department of Gastroenterology, West China Hospital, Sichuan University, Chengdu, China

Corresponding author

\section{Bing Hu, MD}

Department of Gastroenterology, West China Hospital, Sichuan University, No. 37, Guo Xue Xiang, Chengdu, Sichuan, China 610041

Fax: +86-28-85423387

hubingnj@163.com

* These authors contributed equally to this work. Khan, Bing Hu

\section{Bibliography}

DOI https://doi.org/10.1055/a-0624-9277

Published online: 12.6.2018

Endoscopy 2018; 50: E227-E228

(c) Georg Thieme Verlag KG

Stuttgart · New York

ISSN 0013-726X

\section{ENDOSCOPY E-VIDEOS \\ https://eref.thieme.de/e-videos}

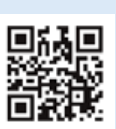

Endoscopy E-Videos is a free access online section, reporting on interesting cases and new techniques in gastroenterological endoscopy. All papers include a high quality video and all contributions are freely accessible online.

This section has its own submission website at https://mc.manuscriptcentral.com/e-videos 